\title{
Youth Participation Through Distributed Discussion
}

\author{
Pille Pruulmann-Vengerfeldt \\ Associate professor, University of \\ Tartu \\ Ülikooli 18 \\ 50090, Tartu. Estonia \\ $+3727375190$ \\ pille.vengerfeldt@ut.ee
}

\author{
Ella Taylor-Smith \\ Edinburgh Napier University \\ Colinton Road, \\ Edinburgh, EH10 5DT \\ +441314552392 \\ itc@napier.ac.uk
}

\author{
Simone Kimpeler \\ Fraunhofer ISI \\ Breslauer Straße 68 \\ 76139 Karlsruhe, Germany \\ +497216809318 \\ Simone.kimpeler@isi.fraunhofe \\ r.de
}

\begin{abstract}
The paper describes an eParticipation project, piloted in four EU countries: Estonia, Germany, Ireland and the UK. HUWY, Hub Websites for Youth Participation, was an initiative where young people were invited to think about current and future problems of the Internet and propose solutions, within the framework of a distributed discussion. This paper reviews this implementation of the distributed discussion model to highlight its possibilities for supporting eParticipation of young people.
\end{abstract}

\section{Categories and Subject Descriptors}

H.1.2 - User/Machine Systems Human factors J.1 ADMINISTRATIVE DATA PROCESSING Government J.4 SOCIAL AND BEHAVIORAL SCIENCES Sociology

\section{General Terms}

Experimentation, Human Factors, Legal Aspects

\section{Keywords}

e-participation, young people, democracy

\section{INTRODUCTION}

It has long been suggested that democracy needs an overhaul and that alienation between state and subjects is a significant problem. Many authors [3, 10] have pointed out that technology could contribute to the solution and attempts have been made to improve the situation, using online technologies. Dahlgren [3] sees online technologies as especially relevant: they can add access and widen availability, plus enable filtering of everyday talk into political action. 'Everyday talk' is where many people make most of their contribution to the public sphere [7]. Due to their extensive Internet use, young people are important stakeholders in policies affecting the Internet, so HUWY aimed to involve young people in discussions on this theme, while piloting a distributed discussion. This paper describes the HUWY project's implementation and evaluation of a distributed discussion model for youth eParticipation. We aim to identify the strengths and weaknesses of the model, through this case study, and end with recommendations for similar projects.

\section{CASE HUWY}

Hub Websites for Youth Participation was a European

Permission to make digital or hard copies of all or part of this work for personal or classroom use is granted without fee provided that copies are not made or distributed for profit or commercial advantage and that copies bear this notice and the full citation on the first page. To copy otherwise, or republish, to post on servers or to redistribute to lists, requires prior specific permission and/or a fee.

ICEGOV2011, September 26-28, 2011, Tallinn, Estonia.

Copyright 2011 ACM 978-1-4503-0746-8...\$10.00.
Commission co-funded eParticipation project, involving four EU countries: Estonia, Germany, Ireland and the UK. The HUWY Consortium included local researchers, youth groups and policymakers as relevant actors [13]. HUWY aimed to find good ways to support groups of young people to discuss what changes are needed to the Internet and its regulation and, further, to encourage policy-makers to interact with young people's ideas. Within the broader theme of Internet policy, young people in each country chose topics in focus group discussions (e.g. Cyberbullying). An "open thread" was also specified for other relevant topics.

The second aim of the HUWY project was to pilot a new method to bring people into policy-making: distributed discussion. This eParticipation model centres on a family of "hub websites". These contain information about the project, well-structured background materials about Internet policy topics, the results of young people's discussions and feedback from policy-makers. There is one hub website for each of the four countries, with localised information and language: that country's central node. Young people hold discussions on their own spaces (satellites in Figure 1 ) in on or offline settings. The four country hubs are linked by an EU hub: a global entry point for the project and place to summarise results for EU policy-makers (http://huwy.eu/).

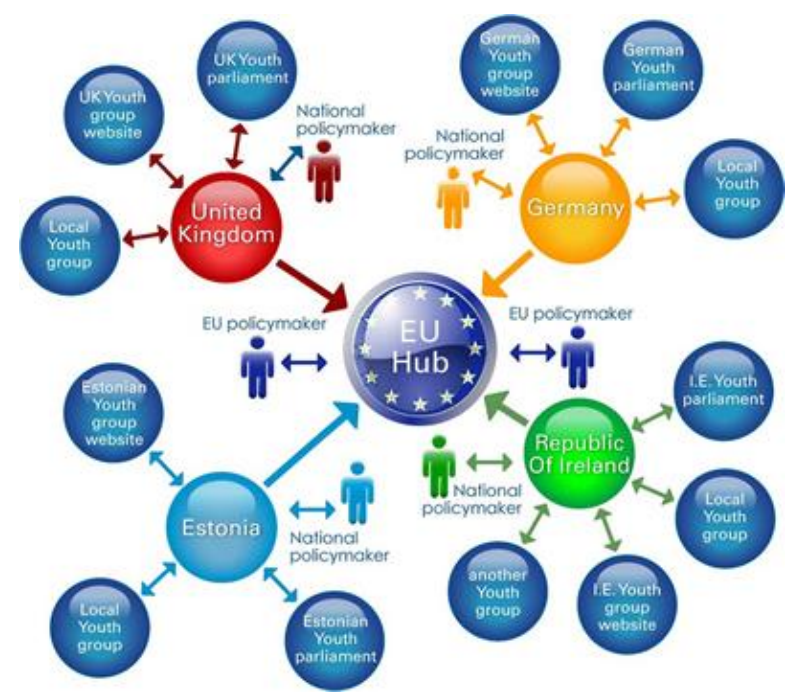

Figure 1: Distributed discussion with national hub websites

The distributed discussion model was devised to be as flexible and inclusive as possible: to enable young people to get involved, while they controlled the format and place. It was designed to include established groups, like youth fora or parliaments, who had their own online spaces and were perhaps already talking about HUWY topics, plus more casual groups, meeting on social networking pages or even offline. This choice of model for input 
into political decision making is partly inspired by Dalhgren [3], Bohman [1], Kim and Kim [7] suggesting the sphere of everyday talk as important for maintaining the larger sphere of common citizenship. This model assumes that people talk policy-relevant ideas in informal settings, online and offline. HUWY tried to motivate participants to create results posts, based on their discussions, for the hub websites, while also identifying relevant policy-makers and encouraging them to read the ideas and provide useful feedback. Direct and measurable impact is unlikely, though the results highlight young people's concerns and provide ideas for inspiration. Youth groups' involvement is encouraged and supported through offline workshops, facilitator training and online resources.

Piloting the distributed discussion model in four diverse countries (Estonia, Germany, Ireland and the UK) enabled the HUWY partners to test their ideas in a variety of contexts. The team in each country were responsible for working with young people to choose the topics; specifying how the pilot should be implemented (online tools and offline processes); providing good quality information in various formats on each HUWY topic and adding this to the hubs through a content management system; promoting the project to young people and youth groups; recruiting, training and supporting facilitators for each discussion group; helping facilitators post results online; promoting results to policy-makers and encouraging them to post feedback. Throughout this, country teams worked with developers to implement and de-bug the online hubs in two revisions (Beta and Gamma). Finally, teams worked together to devise and implement the comprehensive evaluation process and disseminate results.

\subsection{Technical Implementation}

Aiming to create the hub websites out of available open source components, Beta hub websites were created in WordPress. However, as some functionality could not be completed, a Gamma version, created in Drupal, supported the final months and outcomes of the project. Despite some server problems, which caused the websites to be unavailable on a number of occasions, the HUWY project involved a wide range of online and offline activities in four countries. Problems with the online tools caused problems in all aspects of the implementation and partners put additional efforts into offline events. Almost all youth groups seemed to prefer offline discussions, but perhaps more online groups would have been recruited with stronger hub websites.

\section{ELEMENTS OF THE HUWY MODEL 3.1 HUWY Websites}

HUWY discussions about Internet problems and policy solutions could involve complex legal and technical knowledge, as well as touching on matters central to young people's lives. While conducting discussions with young people to identify topics, we discovered that young people had a wealth of experience to share: not always sufficiently grounded in knowledge about technical or legal aspects, to support productive dialogue. Information, in various formats, was designed to attract young people's attention and alert them to topics relevant to their daily lives. Hub websites provided guidance for people organising and facilitating discussions: peer-facilitation guides, tips and agendas. Young people held discussions in their own spaces (online or offline) and posted discussion outcomes (results) on the hub websites. Here, policy-makers working on related themes could find relevant input from young people and respond to the ideas on the hubs.

Each pilot country had a hub website in the local language, with local and localised content, including background materials to support young people's discussions in various formats - text, video, photos, podcasts, and links to outside sources. A total of 242 discussion results were posted on the hubs. Policy-makers gave feedback, via online comments, to 24 of these.

\subsection{Use of Social Networks}

Current EU-sponsored eParticipation pilots trial new ways to use ICTs to involve citizens in policy discussions. Most approaches aim to find an appropriate method mix for reaching participants and increasing their involvement $[9,14,2]$. Web 2.0 applications, principally social networks (SNs) like Facebook, are becoming the most important means of online communication, especially for young people $[4,10]$. Young people use various media for getting information and for communication $[10,12]$. This inspires mixedmedia use to reach this target group. A look at young people in the Social Web illustrates that motivations are related to three main components: identity-management, relation-management and information-management [12].

To obtain deeper insights into the potential of SNs for attracting and mobilising young participants in eParticipation projects, HUWY developed a Chain of Mobilisation model. The starting point for each chain is a stimulus, understood as relevant information, published or communicated on the $\mathrm{SN}$, for example, an eParticipation initiative post on a Facebook page. In the next step, through the social network, other (interconnected) users can be encouraged to pay active attention to the shared information (e.g. via a private message or shared post). Criteria for successful engagement are topic relevance and transparent impact for the target group, as well as the chosen format of the stimulus (text, picture, video, hyperlink). Further, successfully involving people this way varies by frequency of use, number of "friends" or "followers" and by the function used (e.g. messages, wall-posts, like, share, tweet, re-tweet). All phases of the Chain Model are further influenced by versatile individual factors from outside the SN (e.g. general interests in politics, current news and peer group interests). HUWY aimed to use SNs, especially Facebook and Twitter, as important communication platforms to engage young people. However, analysis of SN use within HUWY and similar projects indicates that young people, using the $\mathrm{SN}$, focused on private communication and peer group relationships, rarely recommending or joining HUWY Groups or Pages. HUWY researchers concluded that the current potential of using SNs to actively involve young people in eParticipation initiatives is rather limited. The highest (theoretical) potential occurs when an appropriate stimulus is spread by young people among themselves. Thus, the use of Facebook seems more appropriate for supporting active participants by supplying frequent information, but less useful for mobilising new participants

\subsection{Workshops}

HUWY teams hosted over 50 workshops, of various kinds. Early workshops were designed to introduce HUWY and recruit participants (young people and policy-makers). Another goal was to recruit and train facilitators, for example to use the hub websites and support democratic discussions through peer facilitation methods. Many workshops included live discussions which became part of the distributed discussion. Final workshops aimed to present results and conclude the project. Various workshops included policy-makers, either to help recruit other appropriate policy-makers or to bring young people and policymakers together to talk about internet policy related issues. 


\subsection{Distributed Discussions}

The project gathered 161 discussion groups. We estimate that over 850 young people participated in these discussions, mostly offline, in schools, universities, youth organisations, but also informal settings, such as homes and clubs. One of the key results in evaluating the distributed discussion model is the very small number of online discussions in the HUWY pilot: few participants chose online as their preferred discussion mode. HUWY initially aimed to help set up groups who would discuss the topics over some period of time. Groups could use a 2-stage discussion format, where the first (shallow) stage focused on people's relationship with the Internet, leading to "our experiences" posts. These posts would provide a useful contextual picture for policymakers. From here, groups would move on, deeper, into discussions about specific topics, leading to ideas, even policy suggestions. Background information was provided on the hubs to lead young people through topics in this way, from the personal to a more detailed investigation of each topic. Some countries provided results templates for each stage: early stage results about experiences and later results containing policy ideas for HUWY topics. However, many groups only posted results for the first discussion stage (98 out of 242 posts) or for the second, skipping the other phase. HUWY succeeded in stimulating discussions about Internet experiences, but (especially younger) groups did not continue into deeper, explorations and possible solutions. Perhaps additional time and support could have brought groups together again to continue discussions, from the subjective to the objective level. This further motivation was difficult to provide, especially if groups were not local to the team and due to the limited time available for the project.

\subsection{Policy-Makers' Feedback}

An important aim of the project was to gather feedback comments from relevant policy-makers to the online results posts made by young people. The project was designed to include policy-makers from each country, who could help recruit other policy-makers appropriate to the posts' topics. Policy-makers were to read and comment on results, once the posts were uploaded to the website. Policy-makers were national and local level decision makers, including members of NGOs involved in Internet governance policy. However, policy-maker inclusion, which was highlighted by young people as one of their key success factors, rarely led to successful feedback. Eighteen policy-makers participated in the offline workshops and 22 policy-makers registered on the hub websites. However, only $10 \%$ of results received feedback from 6 policy-makers. The timescales of the project made policy-maker involvement problematic. Teams had too little time to recruit the right policy-makers to comment on the posts. At the same time, the project was too long to align with any specific policy-making processes: when the topics were chosen, it was hard to know what would become priorities in a year's time. For example, music and film file-sharing was the hot topic when topics were chosen, but "wikileaks" put the emphasis on security and freedom of speech. In Ireland and the UK, the financial crisis and changes in government had a negative impact on policy-maker involvement.

\section{EVALUATION}

\subsection{Evaluation Methodology}

Implementation was adapted to the circumstances in each pilot country (Estonia, Germany, Ireland, UK), but exactly the same evaluation methodology was used: each country's team used the same instruments (translated if necessary) to gather comparable data, during the same time period.
The HUWY project established 15 high level objectives. These included objectives based on work with young people and policymakers to investigate their general and specific aims for the project $^{1}$. Key Evaluation Factors were chosen to highlight the most important results. Evaluation instruments were chosen to provide data which indicated the pilot's success in meeting each objective. Instruments were used in triangulation to verify the results across different aspects (political, social and technical) and from the perspectives of various participants (young people, facilitators $^{2}$ and policy-makers) and the project team. Triangulation refers to the use of multiple approaches within one evaluation investigation. Three or more methods were aligned to each detailed objective to provide a structured overview of the results. Methods are derived from various research areas: social and political science, statistics, usability and accessibility studies.

Instruments used: Web statistics, using Google Analytics; Survey instruments, online survey (48); Semi-structured interviews with young people (21), teachers and youth workers (2) and policymakers (3); Text analysis of posts to evaluate the quality of discussions (116 posts) and to give overview of the proposed policy measures ( 80 posts and 109 policy measures); Quantitative data about discussions in all four countries; Success factors templates and workshop reports, completed by HUWY teams.

\subsection{Evaluation Results}

Feedback recorded at workshops, held with young people, youth workers and policy-makers, showed that people were interested in the distributed discussion model as a good participation method. They were enthusiastic about supporting young people to discuss Internet topics with their peers and providing background information and publishing results on the hub websites. However, surveys, interviews and quantitative discussion data reveal that little workshop enthusiasm came to fruition. This is especially true for people who attended workshops in the first half of 2010, when many technical problems were experienced. Without available hub websites to immediately support enthusiasm, it died, even though the project was designed to support offline discussions.

Discussion success factors templates, completed by HUWY teams, indicate that structured support was important for both online and offline discussions, but easiest to provide in local face to face settings. The online-offline dimension of the pilot revealed that offline discussions are vital components of the model.

Survey and interview results show that formal structures supported more successful recruitment and participation: schools, universities and youth groups. These include good opportunities (time, space and staff) for discussions.

Among survey respondents, $79 \%$ agree that distributed discussions enable young people to express their ideas freely, $77 \%$ that this model enables more people to be involved. Only $19 \%$ consider the system too confusing and $25 \%$ think the system requires too much effort.

In the survey, young people evaluated their experience with the project as positive: those who participated confirm it as a valuable experience, giving it an average score of 5.5 out of 7 . For whether

\footnotetext{
${ }^{1} \mathrm{~A}$ comprehensive description of the model and results is available within the project's User Engagement Report http://www.iidi.napier.ac.uk/c/publications/grantid/13363192

${ }^{2}$ Some facilitators were young people, some were trusted adults like youth workers, teachers and lecturers. HUWY staff also facilitated some discussions.
} 
they would recommend the project to a friend, the average score is 5.2 out of 7 .

If we combine these results with inputs from other instruments (interviews and text analysis) we can say that young people who participated in the project felt that it improved their understanding of policy processes and that they were also enthusiastic about possibilities for policy involvement. However, a major limitation of the project was limited reach. Out of an estimated 850 young people, involved across four countries, almost half were Estonian. The project only met its target numbers in $1 / 4$ pilot countries.

Interviews showed that young people appreciated topics being chosen by their peers, making their discussions more relevant. Mostly young people saw participation as part of their selfimprovement and a chance to learn. Thus, while impact on policy was one of young people's most important evaluation factors (and not achieved) rewards centring on individual development may be more realistic individual motivations in future similar projects.

For improvements, participants suggested a more active media campaign and more publicity for the project. Young people favoured structured, face to face, support for their participation.

\section{CONCLUSIONS}

Although the distributed discussion model provides good opportunities and interesting results, it is resource intensive on many levels. Some elements, such as development of the online hubs and provision of supporting information, would benefit from scaling up, as the same resources could support many more groups. Better online tools could also support a more extensive online promotion campaign and encourage links to active online discussions. Discussion group success factors and workshop reports indicate that, overall, it would have been more successful if the online resources had been more stable, available and integrated into the project. However offline discussions, training and events were the most successful part of the pilot. These were really valued by young people. HUWY partners do not think that much of this human engagement work could have been replaced by online tools.

This project confirms in many ways what Gastil [5] claimed: in deliberation, the face-to-face component is very important, due to the complex nature of the political topics and diverse participants. While computer mediated communication has advantages (e.g. avoiding some discrimination based on visible characteristics), our young participants identified the importance of offline discussion components. These brought them together, motivated them to get started, helped them to stay on topic and to focus on solutions. Based on our analysis, we agree with Gastil's conclusion that democratic systems benefit from regular practice of deliberation among citizens.

In order to avoid enlarging the digital divide, future approaches should focus on actions for mobilising young people from all backgrounds. In particular, our experience supports previous findings $[6,8]$ that young people need additional digital skills to be able to participate fully in online environments. While they may have technical skills, they need support in information evaluation, critical thinking and online content creation. These skills are crucial for constructive online participation. The HUWY pilot revealed how much young people valued support for deliberation, on and offline: these young people, although talked of as a "digital generation" [6], still need support to gain the necessary skills to use digital technologies for effective political communications.

\section{ACKNOWLEDGMENTS}

The HUWY project is sponsored by the European Commission under the eParticipation preparatory action EP-08-01-011.

\section{REFERENCES}

[1] Bohman, J. F. 1996. Public deliberation: Pluralism, complexity, and democracy. MIT Press: Cambridge, MA

[2] Charalabidis Y. et al., 2010: MOMENTUM Final Report: eParticipation Projects Consolidated Results url: http ://www.ep- momentum.eu/

[3] Dahlgren, P. 2006. Civic participation and practices: Beyong 'deliberative democracy'. In Researching media, democracy and participation: The intellectual work of the European Media and Communication Doctoral Summer School, N. Carpentier et al Eds. University of Tartu Press, Tartu, 23-34.

[4] Eimeren B. van und Frees B. 2010: Fast 50 Millionen Deutsche Online - Multimedia für alle? (Ergebnisse der ARD/ZDF-Onlinestudie 2010). In: Media Perspektiven. 2010 (7-8), S. 334-349.

[5] Gastil, J. 2000. Is face-to-face citizen deliberation a luxury or a necessity? Political Communication 17, 257-361.

[6] Kalmus, V., Pruulmann-Vengerfeldt, P., Runnel, P., Siibak, A. 2009. Mapping the Terrain of "Generation C": Places and Practices of Online Content Creation Among Estonian Teenagers. Journal of Computer Mediated Communication, 14 (July 4), 1257-1282.

[7] Kim, J. and Kim, E.J. 2008, Theorizing dialogic deliberation: everyday political talk as communicative action and dialogue, in: Communication Theory, 18, pp.51-70.

[8] Livingstone, S. and Helsper, E. 2007. Gradation in digital inclusion: children, young people and the digital divide. New Media and Society 9 (August 4), 671-696 doi: $10.1177 / 1461444807080335$

[9] Macintosh A. 2004: Characterizing E-Participation in PolicyMaking. In: Hawaii International Conference on System Sciences. 2004 (5), 50117a.

[10] MPFS 2010: JIM 2010 : Jugend, Information, (Multi-)Media. Medienpädagogischer Forschungsverbund Südwest. url: http://www.mpfs.de/fileadmin/JIM-pdf10/JIM2010.pdf.

[11] Norris, P. 2001. Digital divide: civic engagement, information poverty, and the Internet worldwide. Cambridge University Press: Cambridge, MA, New York, NY.

[12] Schmidt J.-H., Paus-Hasebrink I. und Hasebrink U. (2009): Heranwachsen mit dem Social Web. Zur Rolle von Web 2.0Angeboten im Alltag von Jugendlichen und jungen Erwachsenen. Bd. 62. Schriftenreihe Medienforschung der Landesanstalt für Medien Nordrhein-Westfalen. Berlin: Vistas Verlag.

[13] Taylor-Smith, E. and Lindner, R. 2010; 'Social networking tools supporting constructive involvement throughout the policy-cycle' in Peter Parycek and Alexander Prosser (eds) Proceedings of EDEM 2010 - Conference on Electronic Democracy, May 7-8, 2010, Danube-University Krems, Austria; pp331-339

[14] Thorleifsdottir A. et al. 2006: Report on current ICTs to enable Participation. In: DEMO-net: Deliverable 5.1.: DEMO-net Consortium. 2006, url: http: //www.demo-net.org 